\title{
Functional response of the fungus Hirsutella rhossiliensis to the nematode, Heterodera glycines
}

\author{
SHU Chi $^{1,2 \dagger}$, LAI YiLing ${ }^{1 \dagger}$, YANG EnCe $^{1}$, CHEN SenYu ${ }^{3}$, XIANG MeiChun $^{1 *}$ \\ \& LIU XingZhong ${ }^{1 *}$ \\ ${ }^{1}$ State Key Laboratory of Mycology, Institute of Microbiology, Chinese Academy of Sciences, Beijing 100101, China; \\ ${ }^{2}$ University of Chinese Academy of Sciences, Beijing 100039, China; \\ ${ }^{3}$ Southern Research and Outreach Center, University of Minnesota, Waseca, Minnesota 56093, USA
}

Received March 12, 2015; accepted March 26, 2015; published online May 29, 2015

\begin{abstract}
Functional response is a key index in determining the population fluctuation in predation. However, the lack of operable research system limits the studies on functional response of fungal predators. Hirsutella rhossiliensis is a dominant parasite of the soybean cyst nematode, Heterodera glycines. In a soil microcosm bioassay, we determined fungal biomass at different days within 21 days after inoculation, and parasitism rate of $H$. glycines by the fungus was determined. The functional response of $H$. rhossiliensis to $H$. glycines was established and found to be Holling's type III, which was influenced by mycelial densities. Meanwhile, we conducted anti-fungal analysis of metabolic fractions extracted from $H$. rhossiliensis to explain the potential mechanism of the intraspecific competition illustrated by functional response. The result of anti-fungal experiments indicated that the fungal predators had more complicated interaction at population level than expected, which might be regulated by self-inhibition metabolite(s). This study was the first functional response study of fungal predators in microcosm. With the increasing recognition of emerging fungal threats to animal, plant, and ecosystem health, the methodologies and hypotheses proposed in this study might inspire further research in fungal ecology.
\end{abstract}

fungal predator, predation index, self-inhibition composition, soybean cyst nematode

Citation: Shu C, Lai YL, Yang EC, Chen SY, Xiang MC, Liu XZ. Functional response of the fungus Hirsutella rhossiliensis to the nematode, Heterodera glycines. Sci China Life Sci, 2015, 58: 704-712, doi: 10.1007/s11427-015-4868-6

In nature, a number of species coexist to form a complex network of interspecific interactions, including antagonistic, competitive, and mutualistic types [1]. Given the major effect on the fitness of these interactions, traits that affect the ability to accomplish or avoid predation are assumed to be under direct and strong selection. Many contemporary ecological and evolutionary biologists believe that predation has played a major role in determining the patterns in the history of life on this planet, such as the increase in the maximum complexity of organisms [2-5]. Here, the term

$\dagger$ Contributed equally to this work

*Corresponding author (liuxz@im.ac.cn; xiangmc@im.ac.cn) "predation" is used to describe an interaction in which individuals of one species kill and are capable of consuming a significant fraction of the biomass of individuals of another species, including finches consume seeds and the parasitoids parasitize their hosts. The population dynamics of predation is sensitive to the precise form of the employed functional response [6-8], which is defined as the number of captured prey per predator per unit time and describes the predator-prey interaction quantitatively. Research on functional responses can be traced back to the early 19th century [9] and the body of knowledge in the area has been well developed. While most of the studies on predation have focused on animal or insect predation, some have also ex- 
amined carnivorous plants and carnivorous fungi that prey on animals, especially insects and nematodes [10,11]. With regard to fungal predators, although studies on taxonomy, evolution, and predatory mechanisms have been reported $[12,13]$, there is still a lack of ecological dynamic models describing the unique predatory interaction.

In the present study, we selected a species of endoparasitic fungi and its host nematode as the research system [14], which would be a good model for the functional response study on fungal-host interaction. The fungus Hirsutella rhossiliensis (Hr) [15] infects second-stage juvenile (J2) of the soybean cyst nematode (SCN, Heterodera glycines), and has been reported to significantly suppress the SCN population in greenhouse experiments [16]. Hr produces conidia that attach to the cuticle of the passing hosts, germinate to penetrate the nematode cuticle, consume the content of the host, and ultimately kill nematode. If detached from the phialides by factors other than the host nematodes, the spores immediately lose infectivity [17].

Studies on functional response of fungal predators are limited due to the lack of basic knowledge and model systems as in macrocosm, i.e., for fungal predators, it is difficult to record the exact number of the predation events. Most of hosts attacked by fungal parasites are much larger than the fungal spores, which obscures the predation until germination of hyphae or death of hosts. Nevertheless, in Hr-SCN system with relatively small difference in the body size between the parasite and host, the predation events can be observed immediately after the attachment of the spores to the passing-by nematode and can be precisely recorded using an inverted microscope. Moreover, the results derived from Hr-SCN system will not vary with the host-stage or parasite-stage as in insect-host systems because the $\mathrm{Hr}$ conidia can only infect SCN J2. We conducted tube soil assays with different fungal mycelial densities and SCN numbers to determine the main factor influencing the predation rate in this system and establish the functional response of Hr. For the quantification of fungi in the soil, we employed quantitative real-time PCR (Q-PCR) with SYBR Green to monitor the dynamics of the mycelia during a 21-day period. The results obtained in this study revealed that the functional response of $\mathrm{Hr}$ to the $\mathrm{SCN}$ host exhibited a Holling's type III and was influenced by fungal population densities. Furthermore, we also observed that the functional response could be used as a quantitative index for measuring intraspecific competition of single fungal colony and that unexpected population-level complicated organization existed among fungal conspecifics.

\section{Materials and methods}

\subsection{Soil preparation}

The soil sample was collected from a corn field in Gaomi County, Shandong Province, and consisted of 52\% sand,
$33 \%$ silt, $15 \%$ clay, and $1.03 \%$ organic matter at $\mathrm{pH} 6.7$. The soil was passed through a 2-mm-aperture sieve and stored at room temperature $\left(22-25^{\circ} \mathrm{C}\right)$ for 2 months before the experiment. SCN was not detected in the soil by wet sieving and sucrose centrifugation [18], and $\mathrm{Hr}$ was not observed on the native nematodes or on SCN J2 added to the soil. The soil was autoclaved at $121^{\circ} \mathrm{C}$ for $30 \mathrm{~min}$ to eliminate nematodes.

\subsection{Fungal and SCN preparation}

The Hr strain OWVT-1, isolated from SCN J2 in Waseca, Minnesota, USA, was prepared for the Q-PCR and tube soil assays. The strain showed potential for density-dependent population dynamics with SCN (unpublished data). The fungal strain was inoculated onto a cellophane membrane on potato dextrose agar (PDA). After 2 weeks at $25^{\circ} \mathrm{C}$, the colonies on the cellophane membrane were placed in sterile water and shaken to remove spores from the conidiophores. The spore suspension was passed through a sieve with $25-\mu \mathrm{m}$ openings, and the spores in the filtrate were adjusted to a concentration of $2 \times 10^{6} / \mathrm{mL}$. A $5-\mathrm{mL}$ aliquot of each spore suspension was added to $100 \mathrm{~mL}$ of liquid medium [19] and cultured on a rotary shaker at $150 \mathrm{r} \mathrm{min}^{-1}$ at $20^{\circ} \mathrm{C}$ for $7 \mathrm{~d}$. The mycelia were collected by centrifugation at $5000 \mathrm{r} \mathrm{min}^{-1}$ and were blended by a tissue blender (DS-1, Shanghai Angni Instruments Meters Co., Ltd, China) at $3000 \mathrm{r} \mathrm{min}^{-1}$ for $30 \mathrm{~s}$. The mycelia were collected in 400 $\mathrm{mL}$ of sterile water and centrifuged at $5000 \mathrm{r} \mathrm{min}^{-1}$ again to collect the slurry. For tube soil assay, the slurry must be fresh without being dry.

The fresh SCN cysts multiplied in the greenhouse were extracted from the soil by centrifugation in $75 \%(\mathrm{w} / \mathrm{v}) \mathrm{su}-$ crose solution at $2500 \mathrm{r} \mathrm{min}^{-1}$. The eggs were released from the cysts by breaking them in a Fisher $40-\mathrm{mL}$ glass tissue grinder and then separated from the debris by centrifugation in a $35 \%(\mathrm{w} / \mathrm{v})$ sucrose solution for $3 \mathrm{~min}$ at $2500 \mathrm{r} \mathrm{min}^{-1}$. The eggs in the supernatant were transferred to an antibiotic solution containing $100 \mathrm{mg} \mathrm{mL}^{-1}$ streptomycin sulfate, 50 $\mathrm{mg} \mathrm{mL} \mathrm{mL}^{-1}$ chlortetracycline, and $20 \mathrm{mg} \mathrm{mL}^{-1} 8$-quinolinol, and maintained at $4^{\circ} \mathrm{C}$. For hatching, the eggs were rinsed with deionized water, and incubated in $4 \mathrm{mmol} \mathrm{L}^{-1} \mathrm{ZnCl}_{2}$ at $22-25^{\circ} \mathrm{C}$. The SCN J2s were collected within $2 \mathrm{~d}$ of hatching, rinsed with sterile deionized water and placed in a 0.04-mm-aperture sieve in $4.5 \mathrm{mmol} \mathrm{L}^{-1} \mathrm{KCl}$ for $30 \mathrm{~min}$ before use in tube soil assays. The active SCN J2s that moved through the sieve were collected in $\mathrm{KCl}$ solution.

\subsection{Standard curve preparation for Q-PCR}

The mycelia of the pure culture of OWVT-1 were collected, and the whole genomic DNA was extracted from $0.5 \mathrm{~g}$ of mycelia using DNeasy Plant Mini Kit (Cat. No. 69104, QIAGEN). The concentration of the purified DNA was ad- 
justed to $1 \times 10^{7} \mathrm{fg} \mu \mathrm{L}^{-1}$ and was 10 -fold serially diluted and subjected to Q-PCR with the final concentrations ranging from $1 \times 10^{2}$ to $1 \times 10^{7} \mathrm{fg} \mu \mathrm{L}^{-1}$ in triplicate. The final Q-PCR reaction mixture of volume $25 \mu \mathrm{L}$ contained $0.5 \mu \mathrm{L} 200$ nmol L ${ }^{-1}$ of each primer, $2 \mu \mathrm{L}$ of $2.5 \mathrm{nmol} \mathrm{L}{ }^{-1} \mathrm{dNTP}, 12.5$ $\mu \mathrm{L}$ of $2 \times$ SYBR Green buffer, $2 \mu \mathrm{L}$ of the DNA template, and $7.5 \mu \mathrm{L}$ of $\mathrm{ddH}_{2} \mathrm{O}$. The primer F419 (5'-GCGCAGTAGCTCCCAGAG-3') and a reverse primer R480 (5'TTGTTTTACGGCGTGACCG-3') were used for the amplification with the following thermal cycling parameters: a denaturation step at $95^{\circ} \mathrm{C}$ for $5 \mathrm{~min}$, followed by 40 cycles at $95^{\circ} \mathrm{C}$ for $15 \mathrm{~s}$ and $60^{\circ} \mathrm{C}$ for $1 \mathrm{~min}$ [19]. The program was conducted in Bio-Rad CFX96 ${ }^{\mathrm{TM}}$ Real-time system. The $C_{\mathrm{t}}$ (cycle threshold) values were plotted against the logarithm-transformed values of different DNA amounts to produce a standard curve.

\subsection{Tube soil assay}

The fresh mycelia slurry was added to the autoclaved soil with final water content of $10 \%$. The soil and mycelia were mixed thoroughly, and $15 \mathrm{~g}$ of soil was placed in a $15-\mathrm{mL}$ polyvinyl chloride tube with a snap-on cap and a drain hole (5-mm diameter) at the bottom. The tubes were placed in plastic boxes containing wet cheesecloth to maintain moisture at $22^{\circ} \mathrm{C}$. Both the plastic boxes and cheesecloth were sterile at the start of the experiment. The mycelial densities were adjusted to $0.0003 \%, 0.002 \%, 0.01 \%, 0.02 \%, 0.1 \%$, $0.2 \%$, and $0.3 \%$ of wet soil weight, and each density had 61 tubes. Three tubes of each mycelial density were sampled at the 3rd, 6th, 9th, 12th, 15th, 18th, and 21st days for DNA extraction. After $21 \mathrm{~d}$ of inoculation to allow the fungus to establish and produce infecting adhesive spores, newly hatched SCN J2s in $1.0 \mathrm{~mL}$ of $\mathrm{KCl}$ solution were added to the soil surface of each tube, and densities of 0,50, 100, 200, $300,400,500,1000,2000$, and 3000 nematodes per tube were used for each of the seven mycilial densities. Three days after inoculation, the SCN J2s were extracted from the soil by wet sieving and sucrose centrifugation [18]. The numbers of fungus-infected and non-infected SCN J2s were determined by examining the SCN J2s with an inverted microscope at $100 \times$ magnification. The predation rate was calculated as percentage of SCN J2 parasitized. The diagrammatic sketch of tube soil assay is shown in Figure S1 in Supporting Information.

\subsection{The population dynamics of $\mathrm{Hr}$ in tube soil assay}

In tube soil assays, fungal DNA was extracted using FastDNA $^{\circledR}$ SPIN Kit for Soil and the FastPrep ${ }^{\circledR}$ Instrument (MP Biomedicals, Santa Ana, CA, USA), but with a mini-bead beater (Biospec Products, Bartlesville, OK, USA) beating at $4200 \mathrm{r} \mathrm{min}{ }^{-1}$ for $90 \mathrm{~s}$ instead of vortexing to break up the cells. The DNA was stored at $-20^{\circ} \mathrm{C}$ before amplification as described for the standard curve preparation.

\subsection{Field data in Minnesota}

Field data from a study on population dynamics of $\mathrm{Hr}$ and SCN in eight soybean field plots in Minnesota, USA, conducted in 1996 (Table S1 in Supporting Information) was fitted to the logistic model and other models [20]. In that study, the samples were collected for 20 weeks at 2-week intervals, the SCN densities were determined by the total number of SCN J2s in $50 \mathrm{~cm}^{3}$ soil, and the fungal densities were estimated as the number of infected SCN J2s in 50 $\mathrm{cm}^{3}$ soil [21].

\subsection{Hr extraction fractions and their anti-fungal activ- ity}

Hr strain OWVT-1 was fermented on rice substrate for $60 \mathrm{~d}$ at $25^{\circ} \mathrm{C}$. The crude extract was extracted using methanol. Fractions were separated using depressed silica gel with different ratios of petroleum ether to ethyl acetate or methanol to ethyl acetate (Table S2 in Supporting Information). The concentration gradients of the fractions for anti-fungal bioassay were set up as $5,2.5,1,0.5,0.25,0.1 \mathrm{mg} \mathrm{mL}^{-1}$, and water as control. For the concentration of $5 \mathrm{mg} \mathrm{mL}^{-1}$, besides Hr OWVT-1, another six fungal species, including Purpureocillium lilacinum, Clonostachys rosea, Trichoderma virens, Penicillium canescens, Fusarium solani, and Hirsutella minnesotensis, that were isolated from the SCN juveniles and eggs were also included in the assay to eliminate the broad spectrum of anti-fungal effect of fractions. Each treatment was represented by three replicates and cultured at $25^{\circ} \mathrm{C}$ for one week.

\subsection{Statistical analysis}

All the data was presented as mean \pm SD. One-way ANOVA was performed by using SPSS, version 19.0, (IBM, Armonk, NY, USA) to confirm the influence of SCN densities on the predation rate in tube soil assays. Multiple comparisons of the diameter of inhibition zone of anti-fungal experiment were conducted based on Duncan test with significant level of 0.05 .

The type of the functional response was determined based on the data obtained from tube soil assay, using logistic regression analysis of the predation rate in relation to the initial density [22] with CATMOD process in SAS (SAS version 9.2, SAS Institute Inc.). To do this, a polynomial logistic regression eq. (1) was fitted to the data:

$$
\frac{N_{e}}{N_{0}}=\frac{\exp \left(P_{0}+P_{1} N_{0}+P_{2} N_{0}^{2}+P_{3} N_{0}^{3}\right)}{1+\exp \left(P_{0}+P_{1} N_{0}+P_{2} N_{0}^{2}+P_{3} N_{0}^{3}\right)},
$$

where $N_{e}$ is the number of prey consumed, $N_{0}$ is the initial 
prey density and $P_{0}, P_{1}, P_{2}$, and $P_{3}$ are the intercept, linear, quadratic, and cubic coefficients, respectively. If the linear coefficient, $P_{1}$, is significantly negative, the predator is considered to display a Holling's type II functional response, and if positive, the predator is considered to present a Holling's type III functional response [23-26]. As the logistic regression analysis indicated that our data fitted Holling's type III functional response, further analyses were restricted to this type. For Holling's type III functional responses, the instaneous discovery area of predator, $a$, is a hyperbolic function of current prey number, $N$, in the most general useful form (eq. (2)):

$$
a=\frac{d+b N}{1+c N}
$$

where $b, c$, and $d$ are constants. This is a more general form of the hyperbolic relationship postulated by Hassell (1978) [27], which is equivalent to eq. (2) with $d=0$. By substituting eq. (2) into the disc equation of Holling (1966) [28] and rearranging it, we can obtain

$$
N_{e}=\frac{d N T+b N^{2} T}{1+c N+d N T_{h}+b N^{2} T_{h}},
$$

where $T$ is the total predation time, $T_{h}$ is the handling time. In general, Holling's type III functional responses can arise whenever $a$ is an increasing function of $N$. Furthermore, the precise form of the model incorporating depletion depends on whether the instaneous discovery area $a$ is a function of the initial density $N_{0}$ or current prey number $N$ [27,29]. The simplest form originates when $a$ is a function of the initial density, as given in eq. (4).

$$
N_{e}=N_{0}\left\{1-\exp \left[\left(d+b N_{0}\right)\left(T_{h} N_{e}-T\right) /\left(1+c N_{0}\right)\right]\right\} .
$$

A nonlinear least square regression (NLIN procedure in SAS, SAS Institute Inc.) was performed to estimate the parameters. For the Holling's type III functional response, the three parameters $(b, c$, and $d)$ must be significantly different from 0 . This will prove important in defining reduced models if the full model is not satisfactory as well as in eliminating parameters from the model.

\section{Results}

\subsection{Population dynamics of $\mathrm{Hr}$ in tube soil assay}

The solutions of $\mathrm{Hr}$ isolate OWVT-1 genomic DNA, with concentration from $1 \times 10^{2}$ to $1 \times 10^{7} \mathrm{fg} \mu \mathrm{L}^{-1}$, were subjected to Q-PCR. The lowest DNA concentration detected was 100 fg with a $C_{\mathrm{t}}$ value of 34 . A standard curve was constructed using $C_{\mathrm{t}}$ value plotted against logarithm-transformed values of the amount of DNA. The decrease in the amount of DNA in the soil presented an exponential trend during the experimental period (Figure 1). Only the mycelial fluctuations of

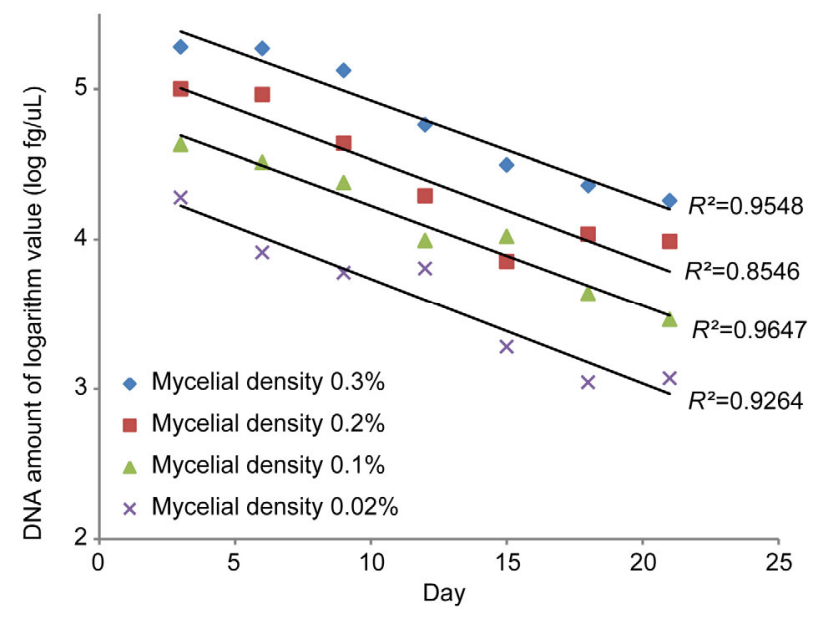

Figure 1 Biomass dynamics within tube soil assay period.

$0.02 \%, 0.1 \%, 0.2 \%$, and $0.3 \%$ could be detected according to the standard curve. The $C_{\mathrm{t}}$ values of each soil sample from Q-PCR were converted to DNA quantities using the standard curve. The DNA amount at a given time point within the experiment time period was positively correlated with the initial fungal amount (Figure 1; Table S3 in Supporting Information).

\subsection{Determination of the type and the parameters of functional response}

In tube soil assay, $\mathrm{SCN}$ J2 number contributed to the change in the predation rate (Tables 1; Table S4 in Supporting Information), indicating a prey-dependent predation. The types of functional response when four mycelial densities were employed to infect SCN were determined using CATMOD procedures in SAS according to the results of detection of mycelia during the 21 days. For all the mycelial densities, the linear parameters $\left(P_{1}\right)$ were positive and the quadratic parameters $\left(P_{2}\right)$ were negative, indicating a Holling's type III functional response, with the predation rate initially increasing and then decreasing with the increasing of $N_{0}$ (Table $\mathrm{S} 5$ in Supporting Information). The results were further verified by plotting the observed mean predation rate along with the predicted predation rate (Figure S2 in Supporting Information). In combination with the field investigation data, the maximum predation rate of $\mathrm{Hr}$ infecting SCN in soil was around 50\%.

The results of NLIN revealed that the significant parameters had asymptotic $95 \%$ confidence intervals that did not include zero. For the full model of all the mycelial densities, the estimates of $b, c$, and $d$ were not significantly different from zero, and a stable model (both $b$ and $T_{h}$ were significant) was achieved after elimination of $d$ (Table 2), resulting in the minimal model for a type III functional response. These results indicated that the relationship between $a$ and $N_{0}$ was linear for all the mycelial densities. The graphic 
presentation of the number of $\mathrm{J} 2$ infected (Figure 2A) indicated a density dependence at low nematode density. However, the functional response curves became asymptotic at different levels for different mycelial densities and the equilibrium values of the functional response curve were quite different from the observed number of infected hosts. Nevertheless, the functional response curves described the observed number of infected host well when being fitted to larger SCN numbers (Figure 2B).

The adjusted $R^{2}$ values of different models in predicting the the field data are presented in Table 3. The logistic model provided a better description of the predation rate than all the other models.

\subsection{Anti-fungal bioassay}

Fifteen secondary metabolite fractions were extracted from $\mathrm{Hr}$ OWVT-1 strains. However, most fractions employed had no effect on the growth of OWVT-1 strain as well as the other six fungal strains except fraction No.3. No.3 fraction had significant self-inhibition effect on OWVT-1 strain, and had relatively weaker inhibition effect on Hirsutella minnesotensis but not on the other five fungal species at the highest dosage tested (Figure 3), indicating an exclusive effect on Hirsutella species. Moreover, the effect was dose-dependent, which strengthened with the increase of the concentrations (Figure 3; Table S6 in Supporting Information).

Table 1 Analysis of ANOVA of predation rate of the soybean cyst nematode by Hirsutella rhossliensis in tube soil assay ${ }^{\text {a) }}$

\begin{tabular}{|c|c|c|c|c|c|}
\hline Mycelial density (\% of soil wet weight) & Factor & Sum of squares & $\mathrm{d} f$ & Mean square & $F$ \\
\hline \multirow{3}{*}{0.02} & Between groups & 0.299 & 8 & 0.037 & $5.460^{* * *}$ \\
\hline & Within groups & 0.185 & 27 & 0.007 & \\
\hline & Total & 0.483 & 35 & & \\
\hline \multirow{3}{*}{0.1} & Between groups & 0.591 & 8 & 0.074 & $12.111^{* *}$ \\
\hline & Within groups & 0.171 & 29 & 0.006 & \\
\hline & Total & 0.762 & 36 & & \\
\hline \multirow[t]{2}{*}{0.2} & Within Groups & 0.118 & 30 & 0.004 & \\
\hline & Total & 1.104 & 38 & & \\
\hline \multirow{3}{*}{0.3} & Between groups & 0.197 & 8 & 0.025 & $17.916^{* *}$ \\
\hline & Within groups & 0.043 & 31 & 0.001 & \\
\hline & Total & 0.240 & 39 & & \\
\hline
\end{tabular}

a) $* *, P<0.01$.

Table 2 Parameter estimation of functional response of Hirsutella rhossliensis to soybean cyst nematode with the data from tube soil assay

\begin{tabular}{cccc}
\hline \multirow{2}{*}{ Functional response parameters } & \multicolumn{3}{c}{ Mycelial density (\% of soil wet weight) } \\
\cline { 2 - 4 } & 0.02 & 0.1 & 0.2 \\
\hline$b$ & 0.00284 & 0.00615 & 0.00695 \\
$T_{h}$ & 28.0593 & 23.9813 & 0.00508 \\
\hline
\end{tabular}
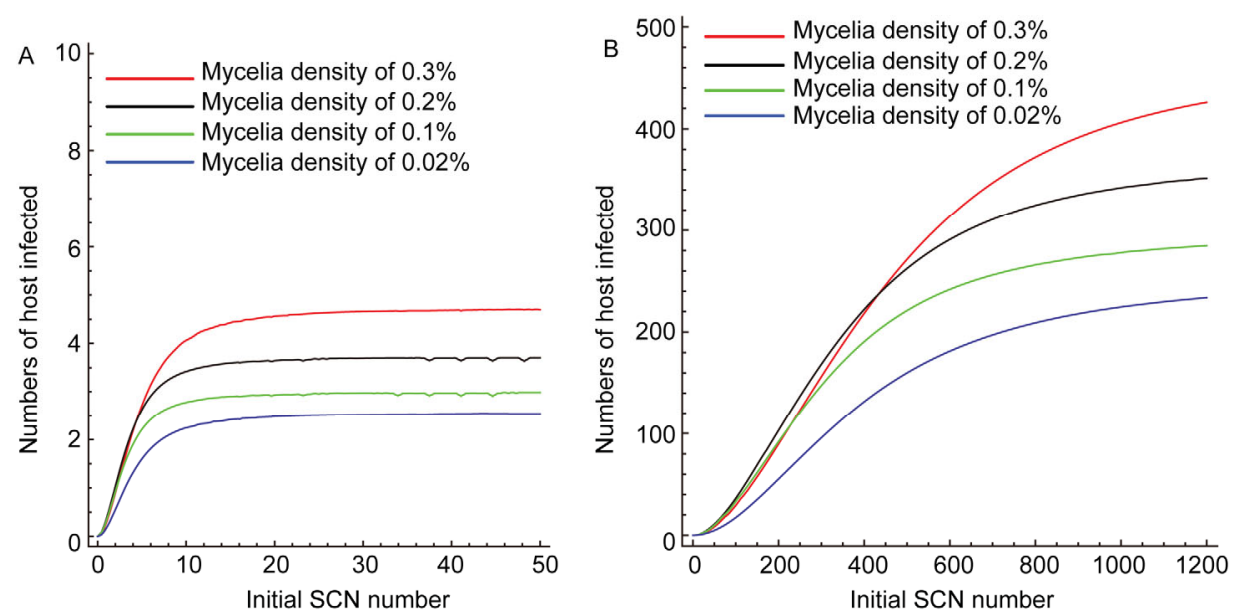

Figure 2 Functional response curves fit by non-linear least squares. A, Original function. B, Functional response curves fitted with higher soybean cyst numbers. 
Table 3 Fitting of predation rate data of the soybean cyst nematode by Hirsutella rhossiliensis using the field data with logistic model and predator dependent models ${ }^{\text {a) }}$

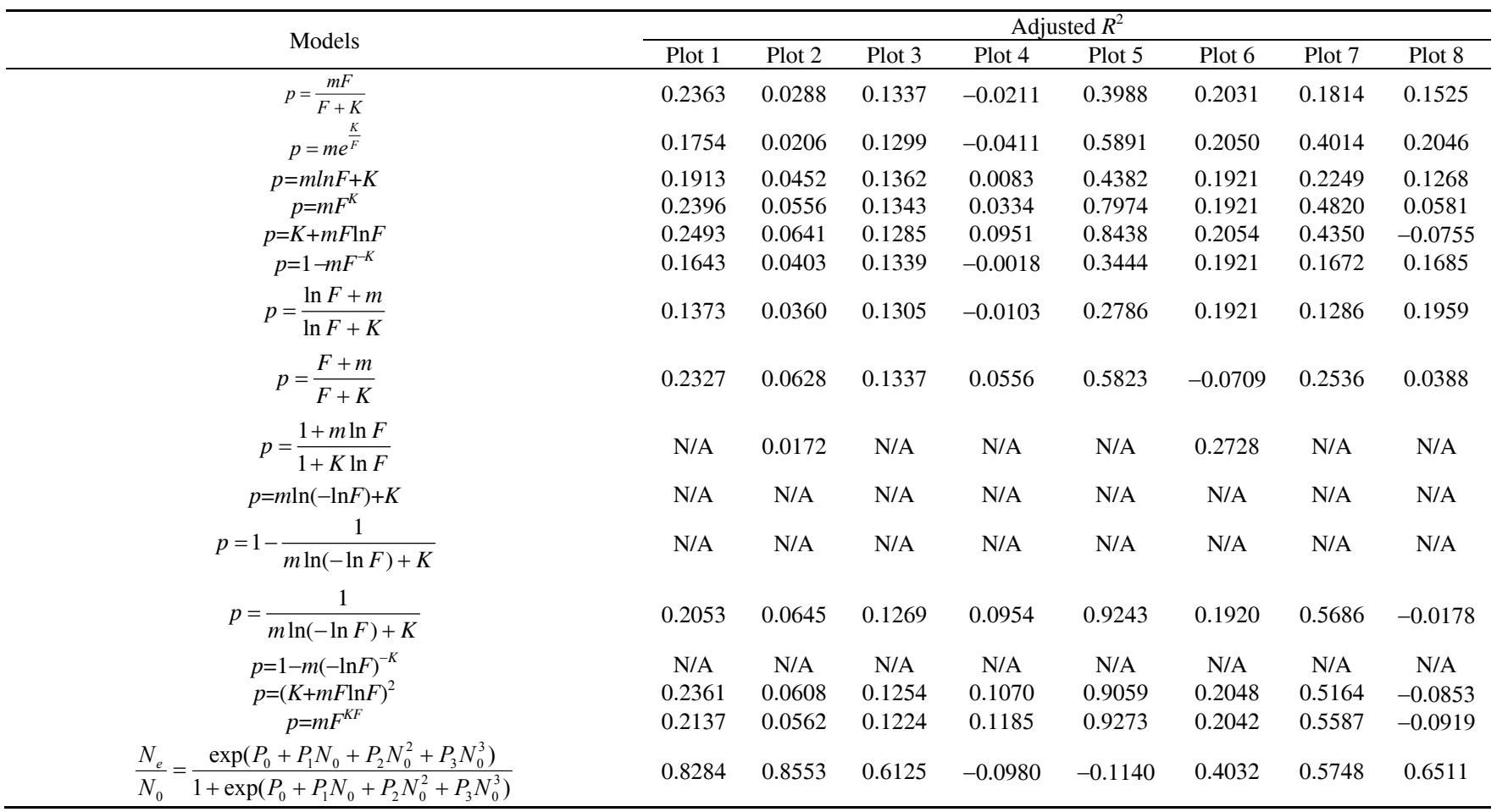

a) $F$, mycelial density; $p$, predation rate.

\section{Discussion}

\subsection{Functional response of $\mathrm{Hr}$ and the intraspecific competition of $\mathrm{Hr}$ quantified by functional response}

Studies on functional response are classical and fundamental in ecology, especially in the field of the population dynamics of predation [28,30-32]. The type of functional response is a key factor in determining the fluctuation pattern in predation relationship [33-36]. While almost all the functional response studies had been conducted in macrocosm with animal or insect predators, those on predators in microcosm, such as fungi or other microorganisms, have been limited due to the lack of sufficient methods as well as the confusions over the basic concepts. However, in the present study, with the model consisting of $\mathrm{Hr}$ and $\mathrm{SCN}$, we developed a novel system for studying the fungal predation. The tube soil assay system was established to mimic the natural soil ecosystem. In the tube soil experiment, the predation events could be precisely determined by extraction of J2 with sucrose-flotation method and observation of the nematodes with an inverted microscope. When compared with animal and insect predators, the prey numbers that could be employed fell into a much larger range, from tens to thousands of SCN, which offered a good opportunity to detect the change in the predation pattern with the variation in the prey population density. Moreover, the results derived from Hr-SCN system will not vary with the host-stage or parasite-stage as in insect-host systems. We also employed multiple predator densities to conform that our results described the predation feature of $\mathrm{Hr}$ instead of an occasional instance.

The mycelial density change in the tube soil assays was measured according to the standard curve of Q-PCR, and the method could semi-quantitatively monitor the population dynamics of $\mathrm{Hr}$ in soil with the lowest initial mycelial inoculum density of $0.02 \%$ of soil wet weight (Figure 1). As the population dynamics of $0.0003 \%, 0.002 \%, 0.01 \%$ mycelial densities could not be detected, predation rate data of these three densities were excluded. The present study is the first to examine the functional response in fungal species. By using the method proposed by Juliano [21-25], the functional response of Hr was inferred to be Holling's type III. In the experimental system employed in this study, $\mathrm{Hr}$ was a sessile predator while SCN was mobile with low mobility. These features make it difficult for $\mathrm{Hr}$ and $\mathrm{SCN}$ to come into contact. Furthermore, SCN are better protected from $\mathrm{Hr}$ in the soil matrix condition because there are more shelters in soil for SCN when either population size is small. This mechanism is identical with that of animals and insect predators with Holling's type III functional response. In the data analysis, parameter $b$ which was in a linear relationship with the instantaneous discovery area, showed an apparent increasing trend while the $T_{h}$ values decreased with the increase in mycelial densities. The change in the two parameters indicated that the $\mathrm{Hr}$ population density influenced 


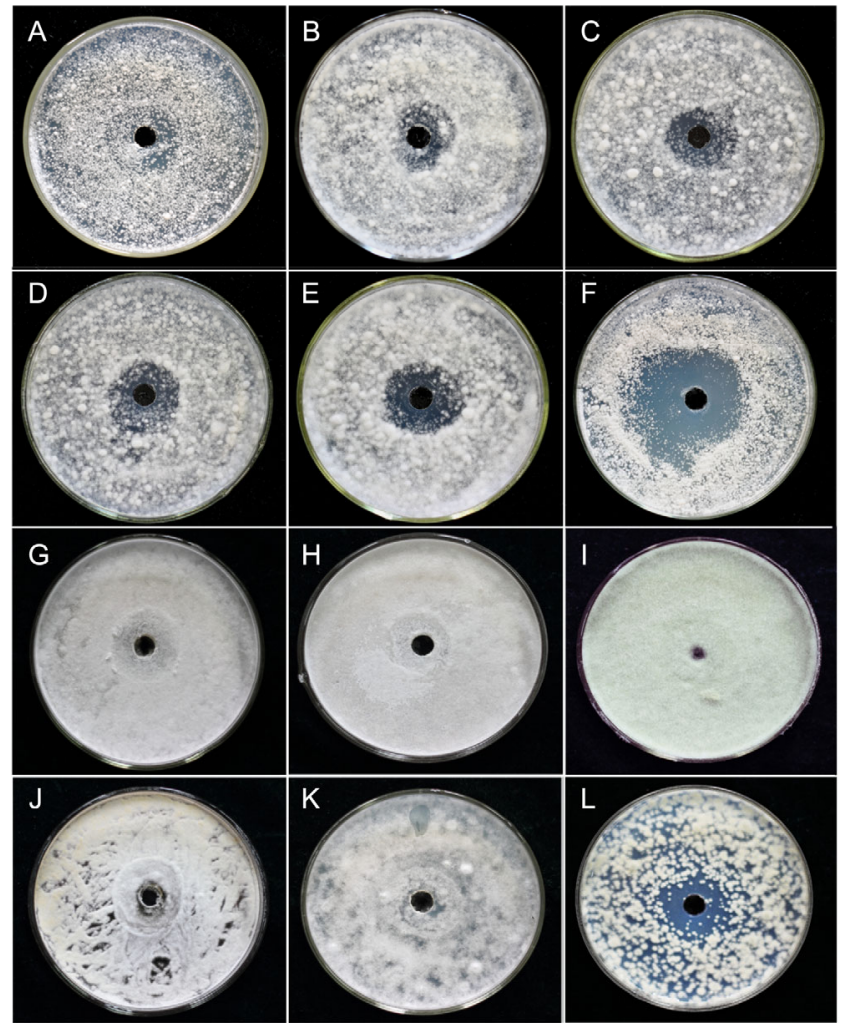

Figure 3 (color online) Anti-fungal bioassay of No.3 fraction from Hirsutella rhossiliensis strain OWVT-1. A-F, The self-inhibition zones of No. 3 fraction on $H$. rhossiliensis strain OWVT-1 at the concentrations of 0 , $0.1,0.5,1,2.5$ and $5 \mathrm{mg} \mathrm{mL}^{-1}$ respectively. G-L, The inhibition of No.3 fraction at $5 \mathrm{mg} \mathrm{mL}^{-1}$ against Purpureocillium lilacinum, Clonostachys rosea, Trichoderma virens, Penicillium canescens, Fusarium solani, and Hirsutella minnesotensis respectively.

predation process to some extent in the tube soil assay. In addition, the functional response curve of $0.3 \%$ mycelial density showed a deceleration in the increase rate of number of prey infected within the range of low SCN numbers (Figure 2), when compared with other mycelial densities, which was noted to be similar to the decrease in the predation efficiency in animal and insect predators resulting from intraspecific competition $[37,38]$.

In most of studies on functional response based on animals and insects, the parameters in the expressions of functional response have some biological meanings, i.e., $b$ relates to the instantaneous discovery area and $T_{h}$ represents the handling time [28]. However, our research system is quite different from the animals and insects, e.g., immobile fungal predators lack the ability to search a certain area to detect their prey, and the handing time is also difficult to define for fungal predators. In order to avoid too much speculative statement, we have added a few sentences to explain the biological meanings based on our understanding. According to the analysis (Table 2), we considered the parameter $b$ as a measurement of the predation efficiency and $T_{h}$ as an indicator of the intensity of the intraspecific competition, instead of handling time. The definitions could explain the change in the pattern of the two parameters in tube soil assay. Furthermore, these two parameters offered a quantitative method to determine the intraspecific competition within $\mathrm{Hr}$ in the predation of SCN.

\subsection{Preliminary analysis of the mechanism underlying the intraspecific competition within Hr OWVT-1 strain}

Although the literatures on fungal competition in general are numerous, most of which focused on the unit-restricted fungi [39], empirical studies on competition among the same filamentous fungal species or even within single fungal isolate are scarce. Previous studies on intraspecific competition among fungi have shown some of the qualitative effects of intraspecific competition on the growth rate, whereas there is still a lack of quantitative studies on other specific life traits. In tube soil assay, only four of the seven datasets obtained were used for the analysis. The population dynamics of the three lowest mycelial densities could not be detected by Q-PCR and data derived from these three densities could not support the basic requirements of the analysis either. Nevertheless, when the mycelial density increased to a certain threshold, which could not be determined in the present study, the predation would meet the analysis requirement of functional response. We defined this certain threshold as the "predation functional unit", representing the mycelial density that could support a stable interaction with SCN. The term is different from the concept "individual" for macroorganism or microorganism with apparent body profile. We established this definition to indicate the accomplishment of a specific behavior, which, in our study, referred to the stable predation behavior that could meet the analysis requirement of logistic method. The present study on the functional response of $\mathrm{Hr}$ was believed to introduce a novel view of fungal intraspecific competition.

When the original functional response expressions of $\mathrm{Hr}$ were fitted with raw predation rate data, it was found that the functions could not explain our experiment results well. This had been primarily taken as the inappropriate choice of models. However, after being fitted to larger SCN numbers, the curves fitted the raw data in a much better manner (Figure $2 \mathrm{~B}$ ). According to previous studies on functional response with animals and insect predators, the functional response expressions should be the description of the predating behavior of a single predator. These studies inspired us that the mycelial densities established for tube soil assay consisted of bulk "predation functional unit", and the raw data were the record of the infecting behavior of several predation functional units infecting behavior together. Based on these analyses, we hypothesized that colonies resulting from the propagules of $\mathrm{Hr}$ in tube soil assay also had a social structure made up of numerous predation functional unit.

In animals and plants, social structure can generate conflict within a population and influence the population structure. Social structure has been revealed even among bacteria [40], and it has been inferred that cohesive population-level 
social organization similar to animal and plant populations may also exist among microorganisms. In the case of filamentous fungi, although such findings have not yet been reported, we believe as a more complicated species compared with bacteria, filamentous fungi should also exhibit reasonable social structure and behavioral attributes. In the anti-fungal experiments, it was noted one fraction of extracts had a significant dose-dependent self-inhibition effect on OWVT-1 while the fraction had little or no negative effect on other strains from the same habitat of $\mathrm{Hr}$ (Figure 3). Considering this as one of the possible mechanisms regulating $\mathrm{Hr}$ predation, it was found the pattern of selfinhibition was identical with the decrease in the predation efficiency (Figures 2 and 3). Besides factors related to growth, other special life traits, such as predation efficiency of $\mathrm{Hr}$ examined in the present study, were also found to be relevant to the population density of filamentous fungi. Those results revealed that fungal species have the potential to regulate their population structure of the same isolate by secreting inhibitory compound and the regulation was density-dependent. However, the main functional component(s) of the fraction remained unidentified, and further research will need to be conducted to elaborate the underlying mechanism of the regulation.

\subsection{Practical application of logistic method in assessing the efficiency of fungal biological control agents}

Although one of the most important methods to assess the efficiency of a natural enemy in regulating the pest populations is to evaluate their behavioral characteristics, including functional response [41,42], this index could be significantly influenced by biological and environmental factors, which makes it difficult to predict the potential of biological control agents. We considered predation rate to be a better index for future assessments because it is a more explicit index for researchers to evaluate the effect of fungal predators on the targeted pests and has been widely used in the assessments of $\mathrm{Hr}$ or other fungal biological control agents $[43,44]$. The fitting of field data by the logistic regression was encouraging (Table 3) and indicated the practical potential of this method for fungal biological control agents. The data collected in 1996 in Minnesota, USA demonstrated that the predation rate in six of the eight plots could be well predicted by logistic regression (Table 3 ). This result is much better than those obtained from the models constructed based on the predation rate data in previous research in our lab [20], among which the best model could only exhibit a good fit with respect to two of eight datasets (Table 3). In the previous study, it was concluded that the predation rate was predator-dependent with the largest nematode density of 12,000 . However, in most cases, according to the present study based on laboratory and field data, it was found that resource is always limited for fungal predators such as $\mathrm{Hr}$ and prey-dependence predation may be the ubiquitous pattern in fungal predators in nature and logistic method is a valuable method to assess the efficiency of fungal biological agents in the future.

In conclusion, the model system of $\mathrm{Hr}$ parasitizing SCN was found to be suitable to study the functional response in microcosm. The results obtained from tube soil assay indicated a ubiquitous existence of Holling's type III functional response in this predation system. Further analyses of the functional response of $\mathrm{Hr}$ revealed the existence of a complicated population level organization in fungal species. To improve the assessment of fungal biological control agents, we conducted the regression of practical predation rate data and found that the logistic regression fitted the field data in a much better manner. The present study was the first to describe a traditional ecological index, functional response, in filamentous fungi. In addition, the study also established a novel research system and proposed some concepts to fulfill the research purpose. However, limited by the materials and techniques, some hypotheses could only be tested with $\mathrm{Hr}$ and SCN. Further studies are required to prove our hypotheses in other taxa to advance the ecological research in filamentous fungi.

The authors declare that they have no conflict of interest.

This work was supported by the National Key Basic Research Program of China (2013CB127506), the National Natural Science Foundation of China (30800732), and the National Public Benefit Research Foundation of China (200903040). The authors thank the staff in platform of secondary metabolism, State Key Laboratory of Mycology for technical supports.

1 Mougi A, Kondoh M. Diversity of interaction types and ecological community stability. Science, 2012, 337: 349-351

2 Gould SJ. Ever Since Darwin: Reflections in Natural History. New York: Norton, 1977

3 Dawkins R. The Extende Phenotype. Oxford: Oxford University Press, 1982

4 Vermeij GJ. The evolutionary interaction among species: selection, escalation, and coevolution. Annu Rev Ecol Evol S, 1994, 25: 219-236

5 Levy CK. Evolutionary Wars. New York: W. H. Freeman, 1999

6 Hulot FD, Lacroix G, Lescher-Moutoue FO, Loreau M. Functional diversity governs ecosystem response to nutrient enrichment. Nature, 2000, 405: 340-344

7 Vos M, Berrocal SM, Karamaouna F, Hemerik L, Vet LEM. Plant-mediated indirect effects and the persistence of parasitoid-herbivore communities. Ecol Lett, 2001, 4: 38-45

8 Gross T, Ebenhoh W, Feudel U. Enrichment and food chain stability: the impact of different forms of predator-prey interaction. $J$ Theor Biol, 2004, 227: 349-358

9 Solomon ME. The natural control of animal populations. J Anim Ecol, 1949, 18: 1-35

10 Thorn RG, Barron GL. Carnivorous mushrooms. Science, 1984, 224: 76-78

11 Albert VA, Williams SE, Chase MW. Carnivorous plants: phylogeny and structural evolution. Science, 1992, 257: 1491-1495

12 Higgins ML, Pramer D. Fungal morphogenesis: ring formation and closure by Arthrobotrys dactyloides. Science, 1967, 155: 345-346

13 Yang Y, Yang EC, An ZQ, Liu XZ. Evolution of nematode-trapping cells of predatory fungi of the Orbiliaceae based on evidence from rRNA-encoding DNA and multiprotein sequences. Proc Natl Acad Sci USA, 2007, 104: 8379-8384

14 Pramer D. Nematode-trapping fungi. Science, 1964, 144: 382-388

15 Minter DW, Brady BL. Mononematous Species of Hirsutella. Trans British Mycol Soc, 1980, 74: 271-282

16 Liu SF, Chen SY. Screening isolates of Hirsutella species for 
biocontrol of Heterodera glycines. Biocontrol Sci Techn, 2001, 11: $151-160$

17 McInnis TM, Jaffee BA. An assay for Hirsutella rhossiliensis spores and the importance of phialides for nematode inoculation. J Nematol, 1989, 21: 229-234

18 Jenkins WR. A rapid centrifugal-flotation technique for separating nematodes from soil. Plant Dis Rep, 1964, 48: 692

19 Zhang LM, Liu XZ, Zhu SF, Chen SY. Detection of the nematophagous fungus Hirsutella rhossiliensis in soil by real-time PCR and parasitism assay. Biol Control, 2006, 36: 316-323

20 Yang EC. Origin and evolution of trapping devices and functional response of nematophagous fungi. Dissertation for Doctoral Degree. Beijing: University of Chinese Academy of Sciences, 2010. 47-48

21 Jaffee B, Phillips R, Muldoon A, Mangel M. Density-dependent host pathogen dynamics in soil microcosms. Ecology, 1992, 73: 495-506

22 Trexler JC, McCulloch CE, Travis J. How can the functional response best be determined? Oecologia, 1988, 76: 206-214

23 Williams FM, Juliano SA. Further difficulties in the analysis of functional response experiments, and a resolution. Can Entomol, 1985, 117: 631-640

24 Williams FM, Juliano SA. Functional responses revisited. Environ Entomol, 1996, 25: 549-550

25 Juliano SA, Williams FM. A comparison of methods for estimating the functional response parameters of the random predator equation. $J$ Anim Ecol, 1987, 56: 641-653

26 Cock MJW. Searching behavior of polyphagous predators. Dissertation for Doctoral Degree. London: Impreial College, 1977

27 Hassell MP. The dynamics of arthropod predator-prey systems. Princeton, New Jersey: Princeton University Press, 1978

28 Holling CS. The functional response of invertebrate predators to prey density. Memiors Entomol Soc Canada, 1966, 48: 1-81

29 Hassell MP, Lawton JH, Beddington JR. Sigmoid functional responses by invertebrate predators and parasitoid. J Anim Ecol, 1977, 46: 249-262

30 Abrams PA. The evolution of predator-prey interactions: theory and evidence. Annul Rev Ecol Evol S, 2000, 31: 79-105

31 Hayes RD, Harestad AA. Wolf functional response and regulation of moose in Yukon. Can J Zool, 2000, 78: 60-66
32 Toscano BJ, Newsom B, Griffen BD. Parasite modification of predator functional response. Oecologia, 2014, 175: 345-352

33 Murdoch WW, Oaten A. Predation and population stability. Adv Ecol Res, 1975, 9: 1-131

34 Williams RJ, Martinez ND. Stabilization of chaotic and non-permanent food-web dynamics. Eur Physi J B, 2004, 38: 297-303

35 Fryxell JM, Mosser A, Sinclair ARE, Packer C. Group formation stabilizes predator-prey dynamics. Nature, 2007, 449: 1041-1043

36 Rall BC, Guill C, Brose U. Food-web connectance and predator interference dampen the paradox of enrichment. Oikos, 2008, 117: 202-203

37 Beddington JR. Mutual interference between parasites or predators and its searching efficiency. J Anim Ecol, 1975, 44: 331-340

38 DeAngelis DL, Goldstein RA, O'Neill RV. A model for trophic interaction. Ecology, 1975, 56: 881-892

39 Schmit JP. Intraspecific competition in two unit-restricted fungal decomposers, Coprinus cinereus and C. congregates. Mycol Res, 2001, 105: $112-118$

40 Cordero OX, Wildschutte H, Kirkup B, Proehl S, Ngo L, Hussain F, Le Roux F, Mincer T, Polz MF. Ecological populations of bacteria act as socially cohesive units of antibiotic production and resistance. Science, 2012, 337: 1228-1231

41 Fathipour Y, Hosseini A, Talebi AA, Moharramipour S. Functional response and mutual interference of Diaeretiella rapae (Hymenoptera: Aphidiidae) on Brevicoryne brassicae (Homoptera: Aphididea). Entomol Fennica, 2006, 17: 90-97

42 Jamshidnia A, Kharazi-Pakdel A, Allahyari H. Functional response of Telenomus busseolae (Hym. :Scelionidae) an egg parasitoid of the sugarcane stem borer, Sesamia nonagrioides (Lep. :Noctuidae) at different temperatures. Biocontrol Sci Tech, 2010, 20: 631-640

43 Jaffee BA, Zehr EI. Parasitic and saprophytic abilities of the nematode-attacking fungus Hirsutella rhossiliensis. J Nematol, 1985, 17: 341-345

44 Zhang LM, Yang EC, Xiang MC, Liu XZ, Chen SY. Population dynamics and biocontrol efficacy of the nematophagous fungus Hirsutella rhossiliensis as affected by stage of the soybean cyst nematode. Biol Control, 2008, 47: 244-249

Open Access This article is distributed under the terms of the Creative Commons Attribution License which permits any use, distribution, and reproduction in any medium, provided the original author(s) and source are credited.

\section{Supporting Information}

Figure S1 Diagrammatic sketch and exhibition of tube soil assay

Figure S2 Mean predation rate of soybean cyst nematode by Hirsutella rhossliensis and fitted relationship produced by logistic regression: A: Mycelial density of $0.02 \%$ of soil wet weight; B) Mycelial density of $0.1 \%$ of soil wet weight; C) Mycelial density of $0.2 \%$ of soil wet weight; D) mycelia density of $0.3 \%$ of soil wet weight. Dots: observed proportions of the infected host; Solid line: fitted relationship produced by logistic regression; Dashed line: fitted relationship produced by logistic regression (regression converged)

Table S1 Original data of the predation of soybean cyst nematode by the fungus Hirsutella rhossiliensis in eight field plots field investigation in 1996

Table S2 Information of the fraction extraction conditions

Table S3 Raw data of Q-PCR

Table S4 Raw predation rate data of tube soil assays

Table S5 Logistic regression of data from tube soil assay-1

Table S6 Effect of different concentration of fraction No.3 on the growth of Hirsutella rhossiliensis OWVT-1 strain (same symbol represents statistically insignificant difference)

The supporting information is available online at life.scichina.com and link.springer.com. The supporting materials are published as submitted, without typesetting or editing. The responsibility for scientific accuracy and content remains entirely with the authors. 